\title{
8. LA PENA DE MUERTE
}

\author{
(Art. 15)
}

\author{
YOLANDA GÓMEZ SÁNCHEZ \\ Profesora Titular de Derecho Constitucional \\ UNED
}


SUMARIO

1. LA PENA de MUERTE: CONCEPTO.-2. LA PENA DE MUERTE EN EL DERECHO COMPARADO Y EN EL ÁMBITO INTERNACIONAL. 2.1. La pena de muerte en Estados Unidos de América y en el Reino Unido: dos modelos. 2.2. El reconocimiento de la pena de muerte en el ámbito internacional. 3. LA PENA DE MUERTE EN EL ORDENAMIENto CONSTITUCIONAL ESPAÑOL-3.1. Precedentes. 3.2. Los trabajos constituyentes. 3.3. La pena de muerte para tiempos de guerra. 3.3.1. Concepto jurídico-constitucional del término guerra. 3.3.2. La guerra como supuesto de Derecho excepcional. 3.3.3. La necesidad de interpretación restrictiva del concepto "guerra": su incorrecta regulación en las leyes penales militares. 4. Propuesta de Reforma CONSTITUCIONAL. 


\title{
8. LA PENA DE MUERTE
}

\author{
(Art. 15)
}

POR

\author{
YOLANDA GÓMEZ SÁNCHEZ
}

Profesora Titular de Derecho Constitucional

UNED

\section{LA PENA DE MUERTE: CONCEPTO}

La pena es una privación o restricción de bienes jurídicos establecida por la ley e impuesta por el órgano jurisdicional competente al que ha cometido un delito '. En la actualidad, presenta dos características esenciales: "que se encuentre establecida por la Ley y que tenga como presupuesto la culpabilidad del sujeto" ${ }^{2}$.

La pena de muerte consiste en la privación de la vida ${ }^{3}$ y ha caracterizado el Derecho penal desde los comienzos de su historia. Acerca de la

1 J. M. Rodríguez Devesa: Derecho Penal español. Parte General. Madrid, 1988, pág. 878.

2 C. García Valdés: Teoría de la pena. Madrid, 1985, pág. 12.

3 E. Gimbernat Ordeig: Estudios de Derecho Penal. Madrid, Civitas, 1980 , pág. 149. Para este autor, la pena puede ser necesaria en una sociedad imperfecta para hacer posible la convivencia humana.

O. N. TIEGHI: Tratado de Criminología. Buenos Aires, 1989, pág. 534. En similar sentido, afirma este autor que la "pena de muerte pertenece al grupo de las sanciones capitales y consiste en la privación forzosa y judicial de la vida humana; ello, en la forma y por los medios regulados en las respectivas legislaciones que la receptan". 
licitud del Estado para imponer la pena de muerte y de la ejemplaridad de ésta se ha discutido y se seguirá discutiendo.

Se alega por un sector de la doctrina que la pena de muerte produce un efecto intimidante, aunque otros estudios criminológicos permiten afirmar que, con frecuencia, tal efecto no se produce ${ }^{4}$, pues las fuertes anomalidades psicopatológicas del delincuente en general, le convierten en un sujeto poco intimidante al que la posible pena de muerte no logra disuadir de sus propósitos ${ }^{5}$.

Igualmente se ha señalado que la sociedad está legitimada para responder con la pena de muerte ante delitos extraordinariamente graves y que la realización de la justicia precisa de esta pena para la restitución del orden jurídico. El propio delincuente, al cometer el delito, se priva a sí mismo de la vida; la sociedad sólo formaliza el proceso letal (Rechtsverwirkungstheorie).

Frecuentemente se estima, en suma, que la privación de libertad no ofrece garantía suficiente ni es pena propia para determinados delitos, para los cuales sólo la pena de muerte resultaría sanción adecuada.

Por el contrario, dos últimos argumentos, pueden, entre otros, señalarse en favor de la abolición de la pena de muerte. El primero es que la abolición de la pena capital, allí donde se ha producido, no genera aumento de delitos graves ni la posibilidad de pena de muerte genera una disminución de los mismos. El segundo, es la posibilidad de error judicial que, ante la máxima pena, no permite reparación posible.

Parte de la polémica acerca de la pena de muerte se centra en su consideración como la máxima pena que puede imponerse por la comisión de un hecho contrario a la ley. Bastaría con modificar este criterio, que se apoya únicamente en que perder la vida es el mayor castigo posible, para que la pena de muerte pierda gran parte de su significación como sanción ejemplar. No es exacto que la muerte sea la manera de castigar más severamente a todo delincuente. Quizá, su reclusión durante un largo período de tiempo — quizá, siempre- pueda suponer un castigo mayor.

En muchos países se avanza hacia la abolición pero no se ha logra-

4 Así opina, por ejemplo, E. Gimbernat Ordeig: Estudios de Derecho Penal, Madrid, Civitas, 1980, pág. 28.

5 G. Rodriguez Mourullo: "Artículo 15. Derecho a la vida", en Comentarios a las Leyes Políticas. Constitución Española de 1978, tomo II, Edersa, 1984, página 322. Este autor señala también la posibilidad de que la incertumbre sobre la aplicación y ejecución de la pena disminuya ese psible efecto disuasor. 
do en otros muchos, alguno de los cuales pasan por ser paradigma de organización democrática ${ }^{6}$.

\section{LA PENA DE MUERTE EN EL DERECHO COMPARADO $Y$ EN EL ÁMBITO INTERNACIONAL}

La pena de muerte está lamentablemente unida a la historia de la humanidad. Se puede decir que, con algunas excepciones notables, no surgen voces discrepantes contra la pena de muerte hasta el siglo XVIII. En bastantes países y durante cientos de años la pena de muerte fue absolutamente aceptada y aplicada muy frecuentemente ${ }^{7}$.

Desde la Edad Media hasta el siglo XVIII el sistema penal en Europa buscaba la venganza pública y el temor. Desde finales del siglo XVII, aunque con matizaciones, comienza a quebrarse la dialéctica acción criminal versus reacción vindicativa y los ordenamientos jurídicos rebajan el número de delitos penados con la muerte ${ }^{8}$.

6 Podemos encontrar defensores y detractores de la pena de muerte en prácticamente todas las épocas. Sin carácter exhaustivo, podemos citar entre los primeros a Bismarck, Rousseau, Balmes, Kant, Santo Tomás, Goethe, Hegel, Manzini, Lutero, Calvino. Entre los segundos a Voltaire, Víctor Hugo, Salmerón (abandonó el cargo de Presidente de la I República española para no firmar una pena capital), Unamuno, y, desde luego, CESARE DE BONESANA (Marqués de Beccaria), que en su obra Dei delitti e delle pene defendió con especial brillantez la abolición de la pena de muerte; su trabajo tuvo enorme repercusión sobre la reforma de la justicia penal.

7 En Roma se acepta la pena de muerte. Las Doce Tablas (s. V a. de C.) contenía diversas disposiciones imponiendo la pena de muerte. En el Derecho germánico, se aplica la pena de muerte, ya se configure como una pena de derecho privado - restitución o venganza por un daño recibido- como de derecho público, cuando se fortalece la estructura estatal.

Algunos representantes de la Iglesia primitiva (Tertuliano, Orígenes, Cipriano, San Atanasio, Lactancio, San Ambrosio, se mostraron reticentes a la aplicación de la pena de muerte. A partir del siglo XII, sin embargo, se acepta la legitimidad de la pena de muerte.

8 En Francia, la Ordonnance Criminelle de 1670, vigente hasta la Revolución Francesa, obligaba a recurrir en apelación toda sentencia de muerte. El Código penal de 1791, redujo los delitos sujetos a pena de muerte de 115 a 32 y estableció, como forma única de ejecución, la guillotina.

En Inglaterra, en la primera década del siglo XIX había más de 200 delitos castigados con la máxima pena. Hacia la mitad del siglo se habían reducido a 15.

Dos de las primeras aboliciones se debieron a Leopoldo II de Toscana (1786) 
El movimiento abolicionista prosigue durante los siglos $\mathrm{XIX}$ y $\mathrm{XX}$, aunque las dos grandes guerras frenarán la desaparición de la pena de muerte. El clima de inseguridad originado por las dos contiendas bélicas, los abusos inevitables en estas circunstancias y el contexto sangriento de todo ello perjudicaron notablemente el camino de la abolición.

Los ordenamientos jurídicos muestran básicamente tres posiciones frente, a la pena de muerte:

a) Su abolición para todos los delitos 9 .

b) Su abolición para los delitos comunes, pero su mantenimiento para delitos o situaciones específicas (leyes militares, delitos políticos o de terrorismo) ${ }^{10}$.

c) Su mantenimiento tanto para delitos comunes como de otra naturaleza ${ }^{11}$.

y a José II de Austria (1787), aunque en ninguno de estos casos la idea abolicionista prendió en las respectivas sociedades.

9 Han abolido la pena de muerte para todo tipo de delitos: Alemania (1949; la extinta República Democrática Alemana en 1987); Australia (1985); Austria (1968); Cabo Verde (1981); Colombia (1910); Costa Rica (1877); Dinamarca (1978); Ecuador (1906); Filipinas (1987); Finlandia (1972); Francia (1981); Haití (1987); Honduras (1956); Islandia (1928); Liechtenstein (1987); Luxemburgo (1979); Mónaco (1962); Nicaragua (1979); Noruega (1979); Países Bajos (1982); Portugal (1976); República Dominicana (1966); San Marino (1865); Santa Sede (1969); Suecia (1972) Uruguay (1907); Venezuela (1863). Datos tomados de D. SERRANo TÁrRAGA: "La pena de muerte" (Tesis Doctoral. UNED, 1991).

10 Algunos paises han abolido la pena de muerte para delitos ordinarios y la mantienen en determinados supuestos, como los delitos de terrorismo tipificados en las leyes militares. Así lo hacen: Argentina (1979); Brasil (1979); Canadá (1976); Chipre (1983); El Salvador (1983); España (1978); Fiji (1979); Israel (1954); Italia (1947); Malta (1971); Nueva Zelanda (1961); Papua Nueva Guinea (1974); Perú (1979); Reino Unido (1973); Suiza (1942). Datos tomados de D. Serrano TárRaga: "La pena de muerte" (Tesis Doctoral. UNED, 1991).

11 Más de 100 países o territorios mantienen (aunque algunos de ellos no han aplicado la pena capital en varios años) tanto para delitos comunes como específicos. Entre estos países podemos citar: Andorra, Afganístán, Angola, Arabia Saudí, Argelia, Bangladesh, Barbados, Bélgica, Bermudas, Birmania, Bolivia, Camerún, Congo, Corea del Norte, Corea del Sur, Costa de Marfíl, Cuba, Chile, China, Egipto, Emiratos Árabes Unidos, Estados Unidos de América, Gabón, Gambia, Ghana, Guatemala, Guinea, Guinea-Bissau, Guinea Ecuatorial, Grecia, Honk Kong, India, Indonesia, Irán, Iraq, Irlanda, Islas Caimán, Jamaica, Japón, Jordania, Kenia, Kuwait, Laos, Líbano, Liberia, Madagascar, Mali, Marruecos, Mauricio, Mauritaria, Mongolia, Mozambique, Namibia, Nepal, Níger, Nigeria, Omán; Pakistán, 


\subsection{La pena de muerte en Estados Unidos de América $y$ en el Reino Unido}

Estados Unidos de América y el Reino Unido han mostrado dos modos distintos de enfrentarse jurídicamente a este problema. El primero mantiene en la mayor parte de sus Estados la pena de muerte. El segundo la conserva exclusivamente para casos excepcionales regulados en antiguas leyes.

A Jeremias Bentham se debe la introducción en el Reino Unido de las tesis abolicionistas del Marqués de Beccaria y la defensa de la erradicación de la pena de muerte. Cuando en 1949, se constituyó en Gran Bretaña ${ }^{12}$ la Royal Commission on Capital Punishment, estaban penados con la muerte los siguientes delitos:

- El asesinato (The Offences Against the Person Act, 1861)

- El incendio o destrucción de barcos y astilleros de Su Majestad (Dockyards... Protection Act, 1772)

- La piratería con violencia (Piracy Act, 1837)

- La alta traición (Treason Act, 1814)

En 1957 se aprobó la Homicide Act, en la que la pena de muerte se circunscribía sólo a determinados delitos. La aplicación de la Homicide Act no representó un aumento en la comisión de delitos graves, lo que favoreció la tesis de la reducción de los delitos castigados con la pena capital.

La máxima pena se suprimió en Inglaterra, Gales y Escocia y se sustituyó por la reclusión perpetua con motivo de la aprobación de la Murder (abolition of Death Penalty) Act, el 9 de noviembre de 1965, durante un período de cinco años, según impuso la Cámara de los Lores. Si en ese plazo -que expiraba el 31 de julio de 1970- el Parlamento no hubiera dispuesto otra cosa se restituiría la vigencia de la Ley de 1957.

Paraguay, Ruanda, Senegal, Singapur, Siria, Somalia, Sri Lanka, Sudáfrica, Sudán, Tailandia, Taiwan, Tanzania, Togo, Tonga, Túnez, Turquía, Uganda, Zaire, Zambia. Datos tomados de D. Serrano Tárraga: "La pena de muerte" (Tesis Doctoral. UNED, 1991).

12 L. ArRoyo Zapatero,: Abolición de la pena capital en Gran Bretaña, obra homenaje al Profesor J. Antón Oneca. Ediciones de la Universidad de Salamanca, 1982. 
El Parlamento volvió a plantearse el problema antes de la finalización del plazo señalado y, por último, el 19 de diciembre de 1969 quedó abolida la pena de muerte en Inglaterra, Gales y Escocia, para el delito de asesinato aunque, de manera extraordinaria, quedaron vigentes las leyes citadas referentes a los delitos de piratería, incendio y alta traición ${ }^{13}$.

Por otro lado, en Estados Unidos la extensión de la pena de muerte depende de las leyes de los distintos Estados. En la actualidad la mayoría de ellos mantienen la pena de muerte para determinados delitos (muerte, violación, etc.) ${ }^{14}$.

Desde hace casi siglo y medio ha habido en Estados Unidos un fuerte movimiento en favor de la abolición de la pena de muerte ${ }^{15}$ que, sin embargo, no ha logrado erradicarla.

El Tribunal Supremo ha tenido ocasión de pronunciarse sobre este tema en varias ocasiones. En $1972{ }^{16}$ se plantea juicio de constitucionalidad sobre la aplicación de la pena de muerte a tres ciudadanos de color; uno condenado por homicidio y dos por violación. El Tribunal declaró que es inconstitucional aplicar esta pena en los casos que le son sometidos porque se vulneraban las enmiendas de la Constitución VIII (prohibición de aplicar penas desacostumbradas y crueles) ${ }^{17}$ y XIV (al considerar el Tribunal que la raza de los inculpados había influido en la sentencia) ${ }^{18}$.

13 Desde entonces ha habido varios intentos legislativos (1975 y 1979) para restablecer la pena de muerte, especialmente para los supuestos de terrorismo, pero ninguno de ellos ha prosperado.

14 En Estados Unidos han abolido la pena de muerte Alaska, Distrito de Columbia, Dakota del Norte, Hawai, lowa, Kansas, Maine, Massachusetts, Míchigan, Minnesota, New York, Rhode Island, Vermont, West Virginia, Wisconsin, además de Puerto Rico, Islas Vírgenes, Samoa Americana y Guayana. Information Please Almanac Atlas de Yearbook. Houghton Mifflin Company, Boston, 1991.

15 El primer Estado que abolió la pena de muerte fue Michigan en 1847 (excepto para los casos de traición).

16 Casos Furman v. Georgia; Moore v. Illinios; Stewart v. Massachussets.

17 La Enmienda VIII de la Constitución de Estados Unidos dice:

"No se exigirán fianzas excesivas, ni se impondrán multas execesivas, ni se inflingirán penas crueles y desusadas".

18 La Enmienda XIV, sección 1, de la Constitución de Estados Unidos dice:

"Todas las personas nacidas o naturalizadas en los Estados Unidos y sometidas a su jurisdicción son ciudadanos de los Estados Unidos y de los Estados en que residen. Ningún Estado podrá dictar ni poner en vigor cualquier ley que limite los privilegios o inmunidad de los ciudadanos de los Estados Unidos; tampoco podrá Estado alguno privar a cualquier persona de la vida, la libertad o la propiedad sin el debido proceso legal; ni negar a cualquier persona que se encuentre dentro de sus límites jurisdiccionales la protección de las leyes, igual para todos." 
Poco tiempo después, en 1976, el Tribunal Supremo revisó su jurisprudencia ${ }^{19}$ afirmando que la pena de muerte no siempre viola las enmiendas VIII y XIV de la Constitución y que las circunstancias habían cambiado desde la resolución de 1972, pues la población mayoritariamente se mostraba de acuerdo en aplicar la pena capital siempre que se determinara primero la inocencia o culpabilidad y luego la existencia de una causa que justificara dicha pena.

Desde entonces se han ejecutado un número importante de penas de muerte en los Estados que la mantienen. Por otro lado, no es infrecuente la ejecución de los llamados delincuentes juveniles (delincuentes menores de 18 años en el momento de cometer el delito, que son ajusticiados al llegar a esa edad) ${ }^{20}$, aunque las normas internacionales coinciden unánimemente en prohibir la imposición de la pena de muerte a los menores de 18 años en el momento del delito ${ }^{21}$.

A nivel federal, se mantiene la pena de muerte en el Código Uniforme de Justicia Militar. Hasta noviembre de 1985 este Código sólo permitía la pena de muerte para delitos cometidos en tiempo de guerra; en esa fecha se promovió una enmienda - The Department of Defense Authorization Act, 1986 - en la que se extiende la pena de muerte al personal militar condenado por espionaje cometido en tiempo de paz.

En lo que se refiere a la forma de ejecución, se aplican preferentemente la electrocución (silla eléctrica) la cámara de gas y, más recientemente, la inyección letal ${ }^{22}$.

Esta sentencia del Tribunal Supremo —dictada por 5 votos contra 4- tomó en consideración la discrecionalidad de que gozaban los Tribunales inferiores que podían optar entre la pena de muerte o una pena de privación de libertad. Por tanto, no quedaban afectados los delitos que de forma imperativa (mandatory) tenían asignada la pena de muerte como sanción única.

19 Caso Gregg $v$. Georgia y cuatro sentencias más. De ellas, tres eran procedimientos discretyonari y dos mandatory.

20 Estados Unidos. Menores condenados a muerte. Madrid. Amnistía Internacional, 1991.

21 Pacto Internacional de Derechos Civiles y Políticos; Convención Americana sobre Derechos Humanos y Convención de los Derechos del Niño de las Naciones Unidas.

22 La inyección letal consiste en la aplicación de tres sustancias sucesivas: pentatol sódico (un barbitúrico); bromuro de pancuronio (un paralizante muscular); y cloruro potásico (que provoca un paro cardíaco).

La Asociación médica de Estados Unidos permite a los médicos actuar en estas ejecuciones sólo como asesores pero no directamente; prescriben el fármaco, asisten a la ejecución, certifican si el reo tiene las venas adecuadas para la aplicación de la sustancia $y$, en su caso, si es precisa una nueva inyección en el caso de que la primera no haya surtido efecto total. 


\subsection{El reconocimiento de la pena de muerte en el ámbito internacional}

El 28 de abril de 1983, quedó abierto a la firma de los Estados miembros del Consejo de Europa, el Protocolo núm. 6 a la Convención Europea de los Derechos del Hombre y de las Libertades Fundamentales (Roma, 1950) en relación con la pena de muerte. El 1 de marzo de 1985 entró en vigor después de ser ratificado por cinco países: Austria, Dinamarca, España, Luxemburgo y Suecia.

Este Protocolo es el primer tratado internacional que prohibe la pena de muerte. En 1989 habían firmado este Convenio otros nueve Estados pero no lo habían ratificado, $y$, siete Estados más, no lo habian firmado ni ratificado.

El 17 de enero de 1986, el Parlamento Europeo instó a los Estados a la ratificación del sexto protocolo sobre la pena de muerte, por el cual los Estados quedan obligados a abolir la pena de muerte en tiempos de paz, aunque permite que el Derecho interno contemple dicha pena en tiempos de guerra o de peligro inminente de guerra ${ }^{23}$.

23 EL sexto Protocolo dice:

«Art. 1: La pena de muerte debe ser abolida. Nadie puede ser condenado a tal pena ni ejecutado.

Art. 2: Un Estado puede prever en su legislación la pena de muerte para los actos cometidos en tiempo de guerra o en peligro inminente de guerra; tal pena no será aplicable más que en los casos previstos por esta legislación y de acuerdo con sus disposiciones. Este Estado comunicará al Secretario general del Consejo de Europa las disposiciones correspondientes de la legislación al efecto.

Art. 3: No se autoriza derogación alguna a las disposiciones del presente protocolo a tenor del artículo 15 del Convenio.

Art. 4: No se admite reserva alguna a las disposiciones del presente protocolo a tenor del artículo 64 del Convenio.

Art. 5: 1. Todo Estado puede, en el momento de la firma o en el momento del depósito de su instrumento de ratificación, de aceptación o de aprobación, señalar el o los territorios a los cuales se aplicará el presente protocolo; 2. Todo Estado puede, en cualquier otro momento posterior, por una declaración dirigida al Secretario general del Consejo de Europa, extender la aplicación del presente protocolo a cualquier otro territorio designado en la declaración. El protocolo entrará en vigor, respecto a este territorio, el primer día del mes siguiente a la fecha de recepción de 


\section{LA PENA DE MUERTE EN EL ORDENAMIENTO CONSTITUCIONAL ESPANOL}

\subsection{Precedentes}

Hasta la aprobación de la Constitución de 1978, España ha mantenido siempre la pena de muerte ${ }^{24}$, con excepción de un breve período de

la declaración por el Secretario general; 3. Toda declaración hecha en virtud de los dos apartados precedentes podrá ser retirada, en lo que concierne a cualquier territorio designado en esta declaración, por notíficación dirigida al Secretario general. La retirada surtirá efecto el primer día del mes siguiente a la fecha de recepción de la notificación por el Secretario general.

Art. 6: Los Estados partes consideran los artículos 1 al 5 del presente protocolo como artículos adicionales al Convenio, $y$ todas las disposiciones del Convenio se aplican en consecuencia.

Art. $7 \mathrm{El}$ presente protocolo está abierto a la firma de los Estados miembros del Consejo de Europa, firmantes del Convenio. Será sometido a ratificación, aceptación o aprobación. Un Estado miembro del Consejo de Europa no podrá ratificar, aceptar o aprobar el presente protocolo sin haber simultánea o anteriormente ratificado el Convenio. Los instrumentos de ratificación, de aceptación o de aprobación serán depositados ante el Secretario general del Consejo de Europa.

Art. 8: 1. El presente protocolo entrará en vigor el primer día del mes siguiente a la fecha en la cual cinco Estados miembros del Consejo de Europa hayan manifestado su consentimiento en estar vinculados por el protocolo, conforme a las disposiciones del artículo 7.2. Para todo miembro que manifieste posteriormente su consentimiento en quedar vinculado por el protocolo, éste entrará en vigor el primer día del mes siguiente a la fecha del depósito del instrumento de ratificación, de aceptación o de aprobación.

Art. 9: El Secretario general del Consejo de Europa notificará a los Estados miembros del Consejo: a) cualquier firma; $b$ ) el depósito de todo instrumento de ratificación, de aceptación o de aprobación; c) toda fecha de entrada en vigor del presente protocolo conforme a los artículo 5 y 8; d) cualquier otro acto, notificación o comunicación que tenga relación con este Protocolo."

24 En nuestra historia la contemplan, por ejemplo, el Liber iudiciorum o Fuero Juzgo; El libro de los Fueros de Castiella; Fueros Viejos de Castilla; Fueros Municipales; Las Partidas; Pragmáticas reales; El Ordenamiento de Alcalá; de Montalvo; Leyes de Toro y de Hermandad, Nueva Recopilación.

La Inquisición, creada por los Reyes Católicos en 1478 y abolida por Fernan- 
tiempo (1932 a 1934), durante la II República, en que fue abolida para delitos comunes ${ }^{25}$.

El régimen de F. Franco la restableció por Ley de 5 de julio de 1938 por considerarla necesaria y que se compaginaba "con la seriedad de un Estado fuerte y justiciero", según reza la exposición de motivos ${ }^{26}$.

El Gobierno, el 19 de abril de 1978, acordó remitir un proyecto de ley "Sobre abolición de la pena de muerte" de tal suerte que ésta se sustituia por la pena de reclusión mayor durante cuarenta años. La Constitución de 1978 elevó a rango constitucional, por primera vez en nuestra historia, la abolición de la pena de muerte (art. 15), si bien es verdad que no de forma absoluta pues se excepciona "lo que puedan disponer las leyes penales militares para tiempos de guerra».

do VII el 9 de marzo de 1920, al comenzar el llamado Trienio Liberal, supuso tres siglos y medio de aplicación de la pena de muerte a los herejes. Los reos del Santo Oficio eran penitenciados y relajados. Los primeros podían salvar su vida mediante las abjuraciones; los relajados podían ser a su vez, reducidos o pertinaces. Los reducidos se arrepentían antes de la ejecución $y$, por ello, recibían garrote antes de ser quemados; los pertinaces eran quemados vivos.

En los Códigos modernos se ha recogido igualmente la pena de muerte. Así se hizo en 1822, 1848, 1850, 1870, 1928, 1944 y 1973. El artículo 83 de este último decia literalmente:

"La pena de muerte se ejecutará en la forma determinada por los Reglamentos.

No se ejecutará esta pena en la mujer que se halle encinta, ni se le notificará la sentencia en que se le imponga hasta que hayan pasado cuarenta días después del alumbramienton.

Sin embargo, tímidamente en el siglo XIX y con mayor firmeza en este siglo, surgieron voces discrepantes con la pena de muerte. Los proyectos de Código Penal de 1854 y 1859 incluían la abolición de la pena de muerte para delitos políticos y los de 1896 y 1904 contemplaban la abolición total.

A partir de los años 70 se levantan voces contra la máxima. El Congreso de la Abogacía, celebrado en León en 1970, solicitó la abolición de la pena de muerte. Este hecho se repite en el Congreso de profesores de Derecho penal, celebrado en Barcelona en 1974.

25 La abolición de la pena de muerte para delitos comunes se publicó en la Gaceta de 5 de noviembre de 1932, pero dicha pena se restableció por Ley de 11 de octubre de 1934 y fue prorrogada por Ley de 20 de junio de 1935.

26 En España, se ejecutaron más de 40 penas de muerte desde 1947 a 1959 por delitos comunes. Con posterioridad a esta fecha no se produjeron ejecuciones por delitos comunes, pero sí bajo la jurisdicción militar.

El Decreto de 25 de noviembre de 1975, de Indulto General, estableció, en su artículo 7, que las upenas de muerte impuestas o cuya imposición proceda por delitos cometidos con anterioridad al día 22 de noviembre de 1975 se conmutarán, o en su caso, serán sustituidas por la inferior en grado en el máximo de su extensión». 
Los modernos Estados, se basan en la proposición de que nadie está legitimado para quitar la vida a nadie, ni siquiera el Estado.

El Estado social y democrático de Derecho (art. 1.1 de la Constitución) se articula en torno a un catálogo de derechos y libertades cuya garantía es el fin principal del Ordenamiento constitucional. Entre todos los derechos constitucionales, la vida se distingue por su naturaleza especial. Que la vida más que un derecho es un presupuesto material para el ejercicio de los demás derechos ha sido señalado por A. TORRES DEL MORAL ${ }^{27}$. Si el Ordenamiento no protege la vida no puede alegar que garantiza realmente ninguno de los otros derechos constitucionales. La pregunta sería, pues, si siendo la regla general la protección de la vida, puede ésta ser suprimida por el propio Estado en casos excepcionales.

Un sector doctrinal defiende que el derecho fundamental a la vida impide que el Estado mate seres humanos, legalice la muerte o de algún modo la permita ${ }^{28}$. Esta prohibición puede desdoblarse en varios aspectos:

a) El deber de respetar las vidas humanas.

b) El deber de proteger las vidas humanas frente a los ataques homicidas procedentes de otros particulares.

c) Muy modernamente, también el deber de garantizar la supervivencia, aunque sea bajo mínimos, de los seres humanos. Así, el derecho a la vida alcanza a un modo de vivir humano, acorde con la dignidad humana. Esto nos lleva a enlazar el derecho a la vida con un derecho de prestación, económico-social ${ }^{29}$.

27 A. TORRes del Moral: Principios de Derecho Constitucional Español, vol 1, Madrid, 1992, pág. 387.

28 G. RODRIGUEZ MOURULLO: "Derecho a la vida y la integridad personal", en Derecho Penal y Constitución, tomo I, Madrid, 1982, pág. 63.

29 G. Rodríguez Mourullo: op. cit. pág. 64, citando a MaUnz-Durigherzog: Frundgesetz. Kommentar. München, 1970, págs. 80-92.

En igual sentido, N. MARTínez Marín: «El derecho a la vida en la Constitución española de 1978 y en el Derecho comparado: aborto, pena de muerte, eutanasia y eugenesia", Revista de la Facultad de Derecho de la Universidad Complutense, 2, monográfico, 1979, pág. 147. 


\subsection{Los trabajos constituyentes}

Durante la elaboración de la Constitución española las fuezas políticas mantuvieron distintas opiniones acerca de la pena de muerte.

En el artículo 15 del Anteproyecto de Constitución no figuraba mención alguna a la pena capital ${ }^{30}$. Unión de Centro Democrático defendió la conveniencia de no constitucionalizar la abolición de la pena de muerte, aunque se declaraba contrario a la misma y en el seno de dicho Grupo Parlamentario se defendieron enmiendas en este sentido ${ }^{31}$, mientras que Alianza Popular mantuvo esta misma tesis y respetó la libertad de voto para sus parlamentarios ${ }^{32}$.

Defendieron, por el contrario, la constitucionalización de la abolición de la pena de muerte los Grupos Parlamentarios Socialistas ${ }^{33}$, So-

30 La redacción del artículo 15 del Anteproyecto decía:

«1. Todos tienen derecho a la vida y a la integridad física.

2. Nadie podrá ser sometido a tortura ni a penas o tratos inhumanos o degradantes".

31 En este sentido, intervención del Sr. Herrero Rodriguez de Miñón en los debates parlamentarios del 13 de mayo de 1978; y enmienda núm. 776 del Diputado Sr. Ales Pérez, de Unión de Centro Democrático, al Anteproyecto de Constitución:

"Todo ser humano tiene derecho a la vida y a la integridad física; en consecuencia se declara abolida la pena de muerte y anticonstitucional cualquier disposición, sea del rango que fuere, que atente contra la vida y la integridad física de la persona humana y del nasciturus". Constitución Española. Trabajos Parlamentarios, vol. I, Madrid, Congreso de los Diputados, 1980 , págs. 1006 y 480.

32 Intervención del diputado Fraga Iribarne en los debates del 18 de mayo de 1978. Constitución Española. Trabajos Parlamentarios, vol. I, op. cit., pág. 990.

33 El Grupo Parlamentario Socialista mantuvo un voto particular de adición ("Queda abolida la pena de muerte») hasta el debate del Pleno del Congreso. Intervención del diputado Sr. Peces-Barba Martínez en los debates del 18 de mayo y de 6 de julio de 1978. Constitución Española. Trabajos Parlamentarios, vol. I, op. cit., págs. 988 y 2009 . 
cialistas de Cataluña ${ }^{34}$, Minoría Catalana ${ }^{35}$, Comunista ${ }^{36}$, Vasco ${ }^{37}$ e integrantes del Grupo Mixto ${ }^{38}$.

La Ponencia no aceptó ninguna de las enmiendas que proponían la incorporación de la abolición de la pena de muerte, aprobando un texto, que se mantuvo en el Dictamen de la Comisión de Asuntos Constitucionales y Libertades Públicas, algo diferente al del Anteproyecto pero en el que no se hacía mención a la pena capital ${ }^{39}$.

Finalmente, la abolición parcial de la pena de muerte se incorporó mediante una enmienda in voce de Unión de Centro Democrático ${ }^{40}$ en el Pleno del Congreso la abolición dejaba a salvo lo que pudieran disponer las leyes militares para las personas sujetas a esa jurisdicción ${ }^{41}$.

34 Intervención del diputado Martín Toval en los debates del 18 de mayo de 1978. Constitución Española. Trabajos Parlamentarios, vol. l, op. cit., pág. 991.

35 Enmienda núm. 113 de Minoría Catalana al Anteproyecto de Constitución: "1. Todos tienen derecho a la vida y a la integridad física. Queda abolida la pena de muerte". Constitución Española. Trabajos Parlamentarios, vol. I, Madrid, Congreso de los Diputados, 1980, pág. 197.

36 Enmienda núm. 692 del Grupo Parlamentario Comunista -Diputado Sánchez Montero- al Anteproyecto de Constitución: "Queda abolida la pena de muerte". Constitución Española. Trabajos Parlamentarios, vol. l, op. cit., pág. 413.

37 Enmienda núm. 598 del Grupo Parlamentario Vasco al Anteproyecto de Constitución: "No podrá imponerse como pena la privación de la vida". Constitución Española. Trabajos Parlamentarios, vol. I, op. cit., pág. 366.

38 Enmienda núm. 64 del Diputado Letamendia Belzunce al Anteproyecto de Constitución: "Queda abolida la pena de muerte".

En igual sentido, enmienda núm. 451 del Diputado Güell de Sentmenat del Grupo Parlamentario Mixto: "Todos tienen derecho a la vida y a la integridad físican; y enmienda 467 del Grupo Parlamentario Mixto: "Queda abolida la pena de muerte". En ningún caso se podrá aplicar la pena de muerte". Constitución Española. Trabajos Parlamentarios, vol. l, op. cit., págs. 166, 312 y 319.

39 La redacción aprobada por la Ponencia y mantenida por la Comisión de Asuntos Constitucionales y Libertades Públicas fue:

"La persona tiene derecho a la vida y a la integridad física, sin que, en ningún caso, pueda ser sometida a tortura ni a penas o tratos inhumanos o degradantes».

40 La enmienda in voce se propuso en el debate del Pleno del Congreso de 6 de julio de 1978 y decía: "Queda abolida la pena de muerte, salvo lo que puedan disponer las leyes penales militares para delitos cometidos por personas sujetas por su propia condición al fuero castrense». Constitución España. Trabajos Parlamentarios, vol. II, op. cit., pág. 2020.

Esta enmienda obtuvo 299 votos a favor de 317, 1 en contra y 17 abstenciones.

41 El texto aprobado por el Pleno del Congreso en la sesión del día 21 de julio de 1978 decía:

"Todos tienen derecho a la vida y a la integridad física, sin que, en nin- 
Diversas enmiendas en el Senado trataron de suprimir esa excepción. Todas ellas fueron rechazadas ${ }^{42}$.

La redacción finalmente acordada en el Congreso -claramente de transacción- presentaba, según un sector de los parlamentarios, una diferenciación que podría resultar discriminatoria en tanto la máxima pena sólo afectaba a los militares con independencia del delito y de que fueran tiempos de guerra o de paz.

El senador J. V. Mateo y Entesa dels Catalans defendieron con éxito sendas enmiendas por las que se suprimía la mención al fuero castrense y se aludía, sin embargo, a la guerra, con el fin de circunscribir exclusivamente la pena de muerte a esta situación y no al fuero militar ${ }^{43}$.

El precepto quedó así claramente perfilado. La Comisión Mixta Congreso-Senado sólo sustituyó "...en tiempo de guerra" por el definitivo "...para tiempos de guerra».

\subsection{La pena de muerte para tiempos de guerra}

\subsubsection{Concepto jurídico-constitucional del término guerra}

Como afirma G. RODRÍGUEZ MOURULLO ${ }^{44}$, «cuando suenan los

gún caso, pueda ser sometido a tortura ni a penas o tratos inhumanos o degradantes. Queda abolida la pena de muerte, salvo lo que puedan disponer las leyes penales militares para delitos cometidos por personas sujetas por su propia condición al fuero castrensen.

42 En este sentido, enmienda núm. 16 de Progresistas y Socialistas Independientes; enmienda 142 del senador C. J. Cela y Trulock; enmienda 451 del senador L. M. Xirinacs; enmienda 1045 de Socialistas del Senado. Estas enmiendas defendieron la abolición total de la pena de muerte, entendiendo que excepción en el caso de tiempo de guerra, entendiendo que no se puede graduar esta pena según las circunstancias. Constitución Española. Trabajos Parlamentarios, vol. II, op. cit., págs. $2676,2720,2854,2950$, respectivamente.

43 La enmienda núm. 106 del senador J. V. Mateo Navarro (Progresistas y Socialistas Independientes) decía: «...Queda abolida la pena de muerte, excepto en las situaciones previstas en caso de guerra".

Entesa dels Catalans (enmienda núm. 774) defendió el texto que finalmente fue adoptado en el Dictamen de la Comisión de Constitución: "...Queda abolida la pena de muerte, salvo lo que puedan disponer las leyes penales militares, en tiempo de guerra". Constitución Española. Trabajos Parlamentarios, vol. II, op. cit., págs. 2710 y 2950 , respectivamente. 
cañones, el Derecho enmudece". La guerra significa siempre muerte y el fracaso del Derecho como instrumento de organizacion pacifica de las sociedades humanas. Este argumento suele utilizarse para explicar el reconocimiento constitucional de la posibilidad de pena de muerte en supuestos de guerra ${ }^{45}$; la guerra se configura así como un verdadero estado de necesidad ante el cual llega a legitimarse la aplicación de la pena de muerte ${ }^{46}$.

Los textos constitucionales en ocasiones silencian el supuesto de guerra; otras veces lo prevén y lo regulan básicamente; los menos, sin embargo, renuncian, como hizo la Constitución de la Il República española ${ }^{47}$, a la guerra como instrumento político.

Como se desprende de los debates constituyentes, la discusión se centró, en su momento, en si debía o no constitucionalizarse la abolición de la pena de muerte y no tanto en si debía o no haber pena de muerte.

La redacción final del artículo 15 no constitucionaliza la pena de muerte ni siquiera para tiempos de guerra. La Constitucion tan sólo dejó abierta esa posibilidad, reconociendo al legislador ordinario un ámbito de discrecionalidad dentro del cual puede incluir o no la máxima pena para tiempos de guerra, posibilidad que, sin embargo, está sujeta a determinados requisitos.

a) Las leyes Penales militares: reserva de ley orgánica

La Constitución exige que la pena de muerte, en su caso, se encuentre incluida en las leyes penales militares.

Si bien el articulo 15 no establece directamente la reserva de ley orgánica para el tratamiento de la pena de muerte, creo que es correcta, por

44 G. Rodríguez MOURULLO: "Artículo 15. Derecho a la vida", Comentarios a las Leyes Politicas.... Constitución Española, vol. II, Madrid, 1984, pág. 326.

45 G. Rodriguez Mourullo: «Artículo 15. El derecho a la vida», Comentarios a las Leyes Politicas..., op. cit., pág. 326 .

46 C. Helfer: Todesstrafe. Berlín, 1975.

47 El artículo 6 de la Constitución española de 1931 decía: «España renuncia a la guerra como instrumento de política nacional".

48 En este sentido, G. Rodriguez Mourullo: "Artículo 15. El derecho a la vida", Comentarios a las Leyes Políticas..., op. cit., págs. 328 y 329; M. COBO DEL RoSAL y T. S. IVES ANTón: Derecho Penal. Parte General, vol. I, Valencia, 1980, págs. 74 Y 134.

En contrario: J. M. Rodríguez DeVeSA: Derecho Penal. Parte General, 11. ${ }^{a}$ edición, Madrid, 1988, pág. 181. 
una parte, la posición de los que defienden la reserva absoluta de ley orgánica (art. 81 de la Constitución) en materia penal ${ }^{48}$, que vincularía a las leyes penales militares - así ha sido entendido por el legislador y, por ello, a la regulación de la pena de muerte- - Y, por otro, resulta ineludible dicha reserva de ley orgánica en el supuesto que comentamos por quedar sustancialmente afectado un derecho fundamental: el derecho a la vida. El Tribunal Constitucional ha delimitado con absoluta claridad que los derechos fundamentales se encuentran en la Sección 1. ${ }^{a}$, del Capitulo II, del Titulo I de la Constitución (artículos 15 a 29) ${ }^{49}$, señalando, además, que las leyes orgánicas son aquellas que los desarrollan de modo directo y no las que meramente los afecten o incidan lateralmente en ellos ${ }^{50}$. La posibilidad de establecer la pena de muerte para tiempos de guerra es una excepción del derecho a la vida reconocido en el mismo artículo 15 de la Constitución y la regulación de esta pena desarrolla sustancialmente - porque lo limita en casos concretos - aquel derecho fundamental.

La posibilidad constitucional de incorporar la pena de muerte para tiempos de guerra se ha materizalizado en la Ley Orgánica 13/1985, de 9 de diciembre, que aprueba el Código Penal Militar, el cual permite aplicar la pena de muerte a los delitos de traición y espionaje militar en tiempos de guerra ${ }^{51}$.

49 SSTC 76/1983, de 5 de agosto, y 160/1987, de 27 de octubre.

50 STC 67/1985, de 26 de mayo.

51 El Código penal Militar, establece la posibilidad de pena de muerte para los delitos de traición y espionaje militar:

"Art. 49. Será castigado con la pena de prisión de veinte a veinticinco años, pudiendo imponerse la de muerte en tiempo de guerra, el militar que:

1. Indujere a una potencia extranjera a declarar la guerra a España o se concertase con ella para el mismo fin.

2. Tomare las armas contra la Patria bajo banderas enemigas.

3. Con el propósito de favorecer al enemigo, le entregase plaza, puesto, establecimiento, instalación, buque, aeronave, fuerza a sus órdenes u otros recursos humanos o materiales de guerra o combate.

4. ${ }^{\circ}$ En plaza o puesto sitiado o bloqueado, buque 0 aeronave o en campaña, ejerciere coacción, promoviere complot o sedujere fuerza para obligar a quien ejerce el mando a rendirse, capitular o retirarse.

$5 .^{\circ}$ Sedujere tropa española o al servicio de España para que se pasen a filas enemigas o reclutase gente para hacer la guerra a España bajo banderas enemigas.

6. Se fugare de sus filas con propósito de incorporarse al enemigo.

7. Con el propósito de favorecer al enemigo, ejecutase actos de sabotaje o, de cualquier otro modo efectivo, entorpeciere gravemente las operaciones bélicas.

8. Propagare o difundiere noticias desmoralizadoras o realizare cualquiera otros actos derrotistas, con la intención manifiesta de favorecer al enemigo. 
Por otro lado, el texto fundamental sólo permite establecer la pena capital para delitos cometidos en una concreta situación que, en el propio artículo 15, se define como tiempos de guerra.

En un Estado de Derecho la guerra no es una noción fáctica, una situación de hecho, un período real de lucha armada, sino que es un concepto jurídico determinado o determinable, y en el actual Ordenamiento jurídico español es, sobre todo, un concepto jurídico-constitucional ${ }^{52}$.

La Constitución española recoge el término guerra en dos ocasiones: en el reiterado artículo 15 y en el artículo 63.3 al establecer que "al Rey corresponde, previa autorización de las Cortes Generales, declarar la guerra y hacer la paz". A este respecto, no cabe ver discrecionalidad alguna en esta función del Monarca; la previa autorización del Parlamento y la necesidad de refrendo la configuran, acorde con una Monarquía parlamentaria, como una facultad tasada. Por otro lado, la autorización de las Cortes Generales sustrae la decisión al Ejecutivo que, en todo caso, deberá someterla al Parlamento, a pesar de que el artículo 97 de la Constitución asigne a aquél la dirección de la política militar y la defensa del Estado. No exige la Constitución mayoría cualificada para esta autorización; bastaría, pues, la mayoría simple de cada una de las Cámaras ${ }^{53}$.

9. Con el ánimo de favorecer al enemigo, causare grave quebranto a los recursos económicos o a los medios y recursos afectados a la defensa militar. 10. De cualquier otra forma, colaborase con el enemigo, préstandole un servicio con el próposito de favorecer el progreso de sus armas.

Art. 50. El español que en tiempo de guerra realizare actos de espionaje militar, conforme a lo previsto en el Capítulo siguiente, será considerado traidor y condenado a la pena de veinte a veintinco años de prisión, pudiendo imponerse la de muerte.

El militar que realizare dichos actos en tiempo de paz será condenado a la pena de diez a veintinco años de prisión.

Art. 52. El extranjero que, en tiempo de guerra, se procurare, difundiera, falseare o inutilizare información clasificada o de interés militar susceptible de perjudicar a la seguridad nacional o a la defensa nacional, o de los medios técnicos o sistemas empleados por las Fuerzas Armadas o industrias de interés militar, o la revelase a potencia extranjera, asociación u organismo internacional, será castigado, como espía, a la pena de quince a veinticinco años de prisión, pudiendo imponerse la de muerte.

La tentativa se castigará con las mismas penas privativas de libertad establecidas para el delito consumadon.

52 Así opina G. Rodríguez Mourullo: "Artículo 15. El derecho a la vida", Comentarios a las leyes Políticas..., op. cit., pág. 327.

53 Curiosamente, el artículo 116 de la Constitución exige mayoría absoluta del Congreso de los Diputados para la declaración del estado de sitio. 
La guerra tiene asi un marco constitucional que viene definido por la apreciación de su necesidad hecha por el Ejecutivo, como responsable de la defensa del Estado; por la autorización de las Cortes Generales y por la declaración formal del Rey. No es guerra en sí misma la lucha armada, general o parcial, abierta o encubierta, externa o interna, organizada o no. La guerra no se identifica con el terrorismo nacional o internacional, ni con las acciones de la guerrilla, ni con ninguna otra alteración, por grave que sea, de la normalidad constitucional. La guerra es, como venimos diciendo, un concepto jurídico y tiene importancia que así sea.

\subsubsection{La guerra como supuesto de Derecho excepcional}

No de forma casual, la Constitución ha incluido, junto a la posible declaración de guerra, el llamado derecho excepcional ${ }^{54}$. Se trata de previsiones, generalmente incluidas en las propias Constituciones para supuestos específicos en los que el Ordenamiento jurídico, las instituciones, o la integridad territorial se encuentren en peligro. La Constitución española (art. 116) establece tres supuestos de derecho excepcional: alarma, excepción y sitio. La Ley Orgánica 4/1981, de 1 de junio, de los estados de alarma, excepción y sitio ha establecido en qué casos es posible declarar dichos estados, el procedimiento y los efectos de cada uno de ellos.

El estado de alarma procede ante catástrofes naturales, crisis sanitarias, ciertas paralizaciones de servicios públicos, o desabastecimiento de productos de primera necesidad, se caracteriza por la ausencia de móviles políticos (art. 4 de la Ley Orgánica). El estado de excepción puede declararse cuando resulten gravemente alterados el ejercicio de los derechos y libertades, el normal funcionamiento de las instituciones democráticas o los servicios públicos esenciales (art. 13.1 de la Ley Orgánica). Y puede ser declarado el estado de sitio cuando "se produza o amenace producirse una insurrección o acto de fuerza contra la soberanía o independencia de España, su integridad territorial o el ordenamiento constitucional» (artículo 32.1 de la Ley Orgánica).

54 Sobre este tema ver, entre otros: I. Berdugo GómEZ DE LA TORRE: "Los estados de alarma, excepción y sitio. Comentario a La ley Orgánica 4/1981, de 1 de junio", Revista de Política Comparada, núm. 5, 1981; P. CRUz VILLALón: Estados excepcionales y suspensión de garantías, Madrid, 1984; F. Fernández SEgADO: «Artículo 55. La suspensión de derechos", en Comentarios a las Leyes Políticas. Constitución Española, tomo IV, Madrid, 1984; J. M. LAFUENTE BALLE: “Los estados de alarma, excepción y sitio", en Revista de Derecho Político, núms. 30, 1989 y 31, 1990. 
El Ordenamiento constitucional español ha previsto, pues, situaciones de alteración grave de la normalidad distintas de la guerra; situaciones de lucha y confrontación armadas, actos de fuerza contra la soberanía o independencia del país, internos o externos, que pueden ser apreciadas no sólo cuando ya se hayan producido, sino cuando exista una expectativa o amenaza. La guerra aparece, así, nítidamente distinta de los estados excepcionales mencionados, distinta incluso de los que podrían serle más cercanos (estados de excepción y sitio). Cada uno de los estados excepcionales posee un presupuesto de hecho, un procedimiento de declaración y unos efectos propios, entre los que se encuentran (para los estados de excepción y sitio) la posibilidad de limitar temporalmente algunos de los derechos y libertades reconocidos en la Constitución.

Creo que puede afirmarse que la guerra participa de la naturaleza del Derecho excepcional, pues regula una situación específica y grave que pone en peligro al Estado y tiene carácter restrictivo tanto en su declaración como en sus efectos. De otro lado, mientras los estados excepcionales (art. 116) se complementan con la posibilidad de suspensión de derechos del artículo 55 de la Constitución, la declaración de guerra (art. 63.3) se completa con la posibilidad de pena de muerte contenida en el artículo 15 del texto fundamental. Por último, en la declaración de los estados excepcionales interviene el Ejecutivo y el Congreso de los Diputados, mientras que para la declaración de guerra se precisa la autorización de las Cortes Generales y la intervención del Rey.

El constituyente podía haber incluido cuatro estados excepcionales en el artículo 116 citado, incorporando así el estado de guerra a los supuestos de derecho excepcional ${ }^{55}$. No lo hizo así, sin embargo. Optó por distinguir, dentro del nivel de máximo peligro para el Estado, dos situaciones: una tiene como respuesta la posible declaración del estado de sitio; otra, la posible declaración de la guerra. El primero se refiere de forma muy principal a crisis dentro del territorio nacional, mientras que la segunda puede acontecer tanto en dicho territorio como lejos del mismo.

Los debates constituyentes nos muestran que, desde el Anteproyecto de Constitución ya figuraba la mención a la declaración de guerra ${ }^{56}$ y que esta redacción suscitó escasa controversia entre los constituyentes.

55 La denominación de estado de guerra como supuesto de derecho excepcional es usual en el Derecho comparado.

56 El artículo $\mathbf{5 5 . 5}$ del Anteproyecto de Constitución decía:

"Al Rey corresponde, previa autorización de las Cortes Generales, declarar la guerra y concluir la paz". 
Sólo el Grupo Parlamentario Comunista defendió una enmienda que incluía los supuestos en que la guerra podía ser declarada ${ }^{57}$.

En este sentido, afirma acertadamente E. PÉREZ VERA que el precepto se redactó "de espaldas a la evolución del Derecho internacional en el tema del uso de la fuerza por los Estados" con un aparente olvido "de la prohibición del uso de la fuerza en las relaciones internacionales, que incorpora el artículo 2, párrafo $4 .^{\circ}$, de la Carta de las Naciones Unidas, cuando, además, el propio Preámbulo de la Constitución, como señala la misma autora, proclama su voluntad de "colaborar en el fortalecimiento de las relaciones pacíficas y de eficaz colaboración entre todos los pueblos de la Tierra ${ }^{58}$.

Más conveniente, sin duda, hubiera sido hacer alguna mención en este sentido en el citado artículo 63.3, como pueden verse en otras Constituciones y como hizo el ya mencionado artículo 77 de la Constitución española de 1931. Pero no lo hicieron así los constituyentes, alejándose de las pautas del Derecho internacional, que, en este punto, lucha por someter «a regulación jurídica el acto esencialmente antijurídico del recurso a la fuerza" ${ }^{59}$, y es por este mismo motivo por el que ha nacido el Derecho de la guerra y el Derecho internacional humanitario ${ }^{60}$, en un intento de atemperar, incluso en la guerra, el sufrimiento de las víctimas.

La guerra ha perdido gran parte de su legitimidad como recurso adecuado - aunque excepcional- en las relaciones internacionales, y ello

57 El Grupo Parlamentario Comunista defendió el siguiente texto alternativo al apartado 5 del artículo 55 del Anteproyecto:

«En caso de agresión externa o amenaza grave para la independencia de España, corresponde al Rey, previa autorización de las Cortes Generales, declarar la guerra. También requerirá dicha autorización para concluir la paz". Enmienda 697. Constitución Española. Trabajos Parlamentarios, vol. I, op. cit., pág. 426.

58 E. Pérez Vera: "Artículo 63. Atribuciones del Rey", Comentarios a las Leyes Políticas. Constitución Española, tomo V, Madrid, 1983, pág. 311.

59 lbidem, pág. 312.

En este sentido hay que interpretar la exigencia de determinados requisitos previos a la declaración de guerra que se recogen en el III Convenio de La Haya, de 18 de octubre de 1970; en el Pacto de la Sociedad de Naciones y en el Pacto de Briand-Kellog, de 27 de agosto de 1928.

60 F. BORY: Génesis y desarrollo del Derecho internacional humanitario. Comité Internacional de la Cruz Roja, Ginebra, 1982, pág. 10. El derecho internacional humanitario nace con la firma del primer Convenio de Ginebra (1864), que fueron modificados y completados en 1906, 1907, 1929 y, finalmente, en 1949, firmados los cuatro actuales Convenios de Ginebra y sus Protocolos. Igualmente deben citarse los trabajos que sobre el derecho de la guerra se celebraron en La Haya en 1907. 
hace que pueda afirmarse que "la declaración de guerra y la misma noción de estado de guerra sean instituciones en crisis a las que los Estados recurren cada vez con menos frecuencia" ${ }^{61}$. Por último, cabe señalar que el Derecho internacional permite a un Estado responder a una agresión armada sin necesidad de declaración de guerra ${ }^{62}$. La previsión del artículo 63.3 de la Constitución aparece así como un reducto anacrónico y alejado de los postulados vigentes en una sociedad que tiende a la supranacionalidad y a la seguridad colectiva. Si, como señala J. M. LAFUENTE BALLE ${ }^{63}$, es muy escasa la posibilidad de que los Gobiernos declaren los estados excepcionales, y más escasa aún es la posibilidad de declaración de guerra y, por ello, también la posible aplicación de la pena de muerte. Estos son, sin duda, argumentos suficientes para defender, como señalaré después, la supresión de las menciones constitucionales a la guerra.

\subsubsection{La necesidad de interpretación restrictiva del concepto "guerra»:} su incorrecta regulación en las leyes penales militares

Que la guerra es una situación prevista en la Constitución claramente distinta del cualquiera de los tres estados excepcionales, especialmente del estado de sitio, creo haberlo argumentado antes. Insistir ahora en que la Constitución prevé la declaración de guerra (art. 63.3) sin mencionar ningún efecto propio de la misma y que establece como presupuesto de hecho para la aplicación de la pena de muerte la existencia de utiempos de guerra", nos llevaría a la disparatada conclusión de que, durante la guerra declarada, no podría aplicarse la pena de muerte (en tanto no haya acciones propiamente bélicas) y que durante el tiempo de guerra - que no guerra formalmente declarada- se podría aplicar la pena de muerte. Creo, por el contrario, que sólo hay una situación jurídico-constitucional más grave que el estado de sitio: la guerra declarada conforme establece la Constitución.

La Constitución española es fundamentalmente garantista en materia de derechos y libertades como corresponde a un texto de sus características y nacido, en gran medida, como reacción un régimen que los limitaba en exceso o simplemente no los reconocía. La posible limitación temporal de los derechos señalados en el artículo 55 de la Constitución

61 E. Pérez Vera: "Artículo 63. Atribuciones del Rey", Comentarios a las Leyes Políticas. Constitución Española, tomo V, op. cit., pág. 312.

62 Artículo 51 de la Carta de San Francisco, en el que se reconoce el derecho a la legítima defensa.

63 J. M. LAFUeNTE BaLle: "Los estados de alarma, excepción y sitio", Revista de Derecho Politico, núm. 31, 1990, pág. 67. 
por la declaración del estado de excepción o de sitio se ve rodeada de toda garantía: declaración temporal por el Congreso mediante mayoría absoluta, responsabilidad de los poderes públicos, garantías procesales, etc. Carece de sentido pensar que esta Constitución garantista permite un estado, "tiempos de guerra", en el que se puede aplicar la pena de muerte, como excepción al derecho fundamental a la vida sin ningún requisito previo, sin garantías procesales - excepto la reserva de ley orgánica- y sin participación del Ejecutivo ni del Parlamento.

Ahora bien, el Código Penal Militar (Ley Orgánica 13/1985, de 9 de diciembre) establece, en su art. 24, como una de las penas principales que pueden imponerse por los delitos comprendidos en dicho Código: la muerte en tiempo de guerra y, antes, el artículo 14 declara, incurriendo, según creo, en una evidente inconstitucionalidad, que:

\begin{abstract}
"A los efectos de este Código se entenderá que la locución "en tiempos de guerra" comprende el período de tiempo que comienza con la declaración formal de guerra, al ser decretada la movilización para una guerra inminente o con la ruptura generalizada de las hostilidades con potencia extranjera, $y$ termina en el momento en que cesen éstas».
\end{abstract}

No considero correcto que este artículo del Código Penal Militar interprete lo que debe entenderse por tiempos de guerra, extendiendo el concepto más allá de lo que la propia Constitución establece, originando con dicha extensión una posible aplicación mayor de la pena capital. Los límites de los derechos fundamentales deben ser siempre interpretados restrictivamente. La pena de muerte es un límite al derecho fundamental a la vida; una excepción a la abolición de la pena de muerte. Su posible regulación, pues, no puede extenderse más allá de lo que el texto fundamental permite de manera expresa.

En el mismo sentido el artículo 25 del citado Código Penal Militar establece:

«La pena de muerte en tiempo de guerra sólo se podrá imponer en casos de extrema gravedad, debidamente motivados en la sentencia y en los supuestos que la guerra haya sido declarada formalmente o exista ruptura generalizada de las hostilidades con potencia extranjeran.

El último párrafo de este precepto creo que adolece igualmente de un vicio de inconstitucionalidad. Estimo que no puede aplicarse la pena de muerte a ningún supuesto sin previa declaración de guerra. La llamada 
ruptura generalizada de las hostilidades con potencia extranjera, no permite, según la interpretación que mantengo, la aplicación de la pena capital.

La redacción del artículo 25 del Código Penal Militar se apoya de forma muy evidente en la redacción del Protocolo núm. 6 del Convenio de Roma, que antes cité, en el cual se permite la máxima pena en tiempos de guerra o situaciones prebélicas. El texto del Protocolo mencionado es el ámbito máximo dentro del cual pueden regular este problema los Estados que hayan ratificado el Convenio y el Protocolo. Si, como sucede en la Constitución española, la redacción de alguno de sus preceptos es ya más restrictiva, ni el Convenio ni sus protocolos habilitan para regular la pena de muerte con más extensión que la que permita la propia Constitucion.

Por otro lado, el artlculo 25 del Código Penal Militar expresamente señala que las hostilidades serán con potencia extranjera, queriendo, quizá, con ello excluir los supuestos de terrorismo interior. Podríamos preguntarnos, por último, si el estado de sitio sería una situación asimilable a tiempos de guerra, pudiéndose entonces aplicar la pena de muerte sin necesidad de declaración de guerra pero previa declaración del estado de sitio. La respuesta, en mi opinión, siguiendo a C. GARCÍA VALDÉS ${ }^{64}$, es rotundamente negativa.

A este respecto debe tenerse en cuenta que la declaración del estado de sitio corresponde al Congreso de los Diputados; la guerra la declara el Rey con autorización de las Cortes (Congreso y Senado). El estado de sitio puede afectar a una parte del territorio, durante un tiempo determinado y con condiciones concretas; la guerra es una situación global y su incidencia en el país está en función de dónde se produzca el conflicto, si dentro o fuera del territorio nacional. Durante la vigencia del Estado de sitio se producen modificaciones de la vigencia de algún derecho o libertad; en la guerra no necesariamente, pues puede ocurrir, como he señalado antes, a muchos kilómetros del territorio nacional.

Con todo, cierta duda podría provenir del artículo 35 de la L. O. 4/1981 de 1 de junio de los Estados de alarma, excepción y sitio que, literalmente, dice:

«En la declaración del estado de sitio el Congreso de los Diputados podrá determinar los delitos que durante su vigencia quedan sometidos a la Jurisdicción Militarn. 
Pero, también en este caso, hay que tener en cuenta que el Código Penal Militar determina que en los casos en que pueda imponerse la pena de muerte (distintos tipos de traición y espionaje militar) sean tiempos de guerra. $Y$ el ya mencionado artículo 14 del Código Penal Militar en ningún caso asimila el estado de sitio a tiempos de guerra.

Por último, diré que, por otro lado, no sólo está sometida al principio de legalidad -en este caso orgánica- el desarrollo del supuesto de pena de muerte para tiempos de guerra, sino igualmente la ejecución de las penas. La ejecución de la pena de muerte no está contenida en el Código Penal Militar.

El artículo 871 del Código de Justicia Militar de 17 de julio de 1945 establecía que la pena capital debía ejecutarse mediante fusilamiento, sin publicidad. El Código de Justicia Militar, sin embargo, ha sido derogado por la sucesiva aprobación de normas de desarrollo constitucional:

- La Ley Orgánica 4/1987, de 15 de julio, de la Competencia y Organización de la Jurisdicción Militar derogó el Tratado I relativo a "Organización y atribuciones de los Tribunales Militares" (arts. 1 a 180) de dicho Código de Justicia Militar, así como los arts. 8 a 14, ambos inclusive, de la Ley Orgánica 9/1980, de 6 de noviembre.

- La Ley Orgánica 13/1985, de 9 de diciembre, de Código Penal Militar derogó el Tratado II, "Leyes Penales" del Código de Justicia Militar de 1945 (arts. 181 a 454).

- La Ley Orgánica 12/85, de 27 de noviembre, del Régimen Disciplinario de las Fuerzas Armadas derogó el Tratado II del Código de Justicia Militar de 1945, en todo lo que se refiere a las faltas militares; el Título XXIV, los Capítulos Primero y Segundo del Título XXV Y el Título XXVI del Tratado III del mismo Código; los apartados 1 y 2 del artículo 7 del Real Decreto-Ley 10/1977, de 8 de febrero, y la Disposición Adicional de la Ley Orgánica 9/1980, de 6 de noviembre, de reforma del Código de Justicia Militar.

- La Ley Orgánica 2/89, de 13 de abril, Procesal Militar derogó en lo subsistente el Tratado III (arts. 455 a 1071) del mencionado Código de Justicia Militar, en el que se contenía el artículo 871 que contemplaba el modo de ejecución de la pena capital, así como el Decreto de 11 de julio de 1934, sobre Detención de Militares, y los artículos $4 .^{\circ}, 5 .^{\circ}$ y $6 .^{\circ}$ de la Ley Orgánica 9/1980, de 6 de noviembre. 
La mencionada Ley Orgánica Procesal Militar de 1989 (arts. 338 y siguientes) regula lo referente a la ejecución de las sentencias, distinguiendo las disposiciones generales (capítulo l); la ejecución de las penas privativas de libertad (capítulo II) y la ejecución de las demás penas (capítulo III), sin que figure la forma de ejecución de la pena de muerte. Siendo inexcusable, como ya se expuso, que también el sistema de ejecución de la pena capital se encuentre contenido en una ley orgánica, cabe señalar el vacío que en este punto presenta la legislación actual.

La Constitución, por último, no señala quién puede ser sujeto pasivo de la pena capital. Como ya hemos señalado, en los debates constituyentes se manejó la idea de mencionar al sujeto haciendo referencia a los que estaban sujetos a la jurisdicción militar. No es el caso del definitivo artículo 15 de la Constitución. La referencia a las leyes penales militares supone exclusivamente que será en ellas donde se regule la pena, pero no que ésta sólo pueda aplicarse a militares. Así se ha entendido en la legislación de desarrollo, ya que el art. 52 del Código Penal Militar al definir el delito de espionaje militar (por el que puede imponerse la pena de muerte) establece que el sujeto del mismo será "el extranjero que, en tiempo de guerra" difunda información que ponga en peligro la defensa nacional. Dificultad adicional es saber quién es hoy extranjero respecto de un español, ya que los modernos acuerdos de Maastricht han extendido ciertos derechos a los antes extranjeros.

\section{PROPUESTA DE REFORMA CONSTITUCIONAL}

Por todo lo dicho en las páginas anteriores, considero que la Constitución española debería haber omitido las referencias a la guerra, con lo que se habría colocado en la línea más progresista del Derecho internacional y, por otro lado, habría consolidado la idea de que el Estado democrático renuncia a quitar la vida a los individuos, estableciendo otros sistemas punitivos para los supuestos más graves. Por ello, propongo:

a) La supresión del artículo 63.3

b) En coherencia con la propuesta anterior, el artículo 15 de la Constitución también debería ser modificado, eliminando la excepción de la pena de muerte para tiempos de guerra. He intentado señalar la dificultad de la aplicación jurídicamente correcta de este precepto y la ten- 
dencia generalizada de los Estados actuales a no declarar formalmente la guerra, junto a la dificultad adicional de distinguirla de algunos supuestos de Derecho excepcional. Por ello, propongo la siguiente redaccion del artículo 15:

«Todos tienen derecho a la vida y a la integridad física y moral, sin que, en ningún caso, puedan ser sometidos a tortura ni a penas o tratos inhumanos o degradantes. Queda abolida la pena de muerte». 